\title{
Prevalence of Consumption of Addictive Substances Among Students of Islamic Azad University (Zahedan Branch)
}

\author{
Seyed Ali Akbar Refahi,, ${ }^{1,}$ Mohsen Hosseinbor, ${ }^{2}$ Zainab Poudineh, ${ }^{3}$ Mohammad Sharif Hosseinbor, \\ and Samira Masumian ${ }^{2}$ \\ ${ }^{1}$ Nabi Akram Hospital, Zahedan, IR Iran \\ ${ }^{2}$ Iranshahr University of Medical Sciences, Iranshahr, IR Iran \\ ${ }^{3}$ Kerman University of Medical Sciences, Kerman, IR Iran \\ "Corresponding author: Seyed Ali Akbar Refahi, Nabi Akram Hospital, Zahedan, IR Iran. Tel: +98-9153418546, E-mail: refahi1360@yahoo.com
}

Received 2014 October 30; Revised 2015 May 16; Accepted 2015 May 20.

\begin{abstract}
Background: The use of addictive substances is one of the most important problems of human societies and one of the major challenges for the social, health, and political realms. Although the problem is not confined to specific age groups, young people at risk are among the main groups.

Objectives: This study examined the frequency of using alcohol and substances among students of Islamic Azad university in Zahedan in 2012.

Patients and Methods: This cross-sectional study included 1,014 students studying at the Islamic Azad university, Zahedan, using cluster sampling and distribution based on gender, college, and graduate level using the high-risk behaviors questionnaire. Demographic data were collected using a questionnaire.

Results: Smoking prevalence rates among female and male students were $6.80 \%$ and $39.1 \%$, respectively. The prevalence of water pipe smoking in female students was $26.1 \%$, and for male students, it was $56.7 \%$. About $4.7 \%$ of female and $21.6 \%$ of male students reported using alcohol at least one or more times. The prevalence rates of drug use were $2.4 \%$ and $13.5 \%$ among female and male students, respectively.

Conclusions: The study results indicate a high prevalence of drug use among students. Thus, it is suggested that preventive and therapeutic interventions for university students are important and necessary.
\end{abstract}

Keywords: Behavior, Addictive, Drugs, Smoking, Alcohol

\section{Background}

Addiction is a condition that results in significant harm to the individual and to society as a whole (1). Substance abuse is a prevalent phenomenon all around the world and has affected human society as the most important cause of "social damage" (2). Clearly, drug abuse and alcohol use in young adults represent a major public health problem. For young people, alcohol and drug abuse interferes with their cognitive and emotional development, increases the chance of accidental injury and death, and magnifies the likelihood of drug dependency. For adults, drug abuse is associated with lung cancer, coronary heart disease, acquired immune deficiency syndrome (AIDS), violent crime, child abuse, and unemployment (3).

The results of cohort studies have shown that alcohol use, marijuana use, and sex with multiple partners increase during the transition from high school to college (4). Studies in the United States indicated that $63.1 \%$ of college students had used alcohol in the past 30 days, while $16.6 \%$ and $14.5 \%$ of students reported past 30-day use of to- bacco and marijuana, respectively (5). The lifetime prevalence rate of any substance use among college students in western Kenya was $69.8 \%$, while the lifetime prevalence rate of alcohol use was $51.9 \%$. Moreover, $97.6 \%$ of alcohol users had consumed alcohol in the week prior to the study (6).

Recent research has indicated the frequencies of the experience of alcohol, traditional narcotics (e.g., opium and marijuana), and psychedelics (e.g., ecstasy) to be $15.1 \%$, $3.1 \%$, and 5.6\%, respectively, among adolescents in Tehran, Iran. In addition, the results of multivariate logistic regression indicated that low parental control rather than medium control (AOR: 0.09), lifetime cigarette use (AOR: 10.41), having a tobacco user friend (AOR: 4.36), and having an alcohol user friend (AOR: 5.84) are factors that are significantly related to the experience of alcohol use in female adolescents (7). The results of another study showed the incidences of first experience of water pipe smoking (hookah), chewing tobacco (Nas), tramadol, drugs, and alcohol were $21.5 \%, 6.1 \%, 4.7 \%, 4.2 \%$, and $7.2 \%$, respectively. The

Copyright ( $)$ 2016, Zahedan University of Medical Sciences. This is an open-access article distributed under the terms of the Creative Commons Attribution-NonCommercial 4.0 International License (http://creativecommons.org/licenses/by-nc/4.0/) which permits copy and redistribute the material just in noncommercial usages, provided the original work is properly cited. 
results also showed that $3.5 \%$ of the students started smoking in 2010. In addition, lifetime experience and annual incidence of these behaviors was $2-5$ times more likely among adolescents with a family member or a friend who used substances compared with those without a history of substance use. Furthermore, such behaviors were 2 - 3 times higher in adolescents with abnormal general health compared with normal ones (8). The results of a study among university students in Iran showed that about 15\% of participants had used substances in the past month and $15.1 \%$ in the last year. Tobacco was the most commonly used substance (19.2\%). The second and third most commonly used substances were opium (15.4\%) and alcohol (10.8\%)(9). Statistical evidence indicates that $34 \%$ of divorces in the country stem from addiction and its related problems (10).

The accelerated development of drug abuse and related problems in students' society and its harmful outcomes, such as a lack of academic motivation, educational failure, physical and psychological diseases, suicide, reckless driving, destruction of public property, abusive behaviors, feeling of a lack of identity, and hazardous sexual behavior, are indicative of the necessity for planning and preparing preventive interventions in universities $(11,12)$. However, provision for any kind of planning requires an understanding of existing conditions and the recognition of the current situation of drug abuse among students. Nowadays, experts consider that epidemiological reviews are the first step in designing preventive plans (13).

The number of studies on substance use among Iranian university students in the epidemiological field is limited; moreover, in some research, methodological insufficiencies have been observed. In most of the studies that have been conducted, substance use outbreak indexes have not been observed in accordance with the current outbreak estimation indexes that is, outbreaks during the lifetime, last year, and last month which were considered in this research.

\section{Objectives}

The present research aims to provide an epidemiological review of substance use in students at Islamic Azad university in Zahedan, Iran.

\section{Patients and Methods}

The present research was carried out using the descriptive sectional method. The population under study included all male and female students of the Zahedan branch of Islamic Azad university who were studying in 2011 - 2012 academic year.
Statistical sampling was carried out based on cluster sampling and distribution of gender, faculty, and degree, with a total number of 1,025 individuals. Compiled data were analyzed via the descriptive statistics method and Ksquare statistical test, in addition to the logistic regression method.

\section{Results}

In total, 1,025 questionnaires were distributed; 11 of these were excluded because of gaps and inconsistencies in the responses, so that 1,014 questionnaires were analyzed. It was found $74.1 \%$ of the respondents were studying for a bachelor's degree, $23 \%$ for an associate's degree, and $2.9 \%$ for a master's degree. Furthermore, 21.1\% were aged 18 - 20 years, $26.2 \%$ were 20 - 22 , and $51.6 \%$ were 22 or older.

In the current study, outbreak of cigarette smoking during the life period of the students was $22 \%$, in the last year it was $11.7 \%$, and in the last month it was 7.6\%. In this research, alcoholic drink usage was rated as $12.6 \%$ for the life period, $7 \%$ for the last year, and $4.1 \%$ for the last month.

The present research showed that hookah smoking was prevalent among students at levels of $40.4 \%, 27.1 \%$, and $15.3 \%$ for the life duration, the last year, and the last month, respectively.

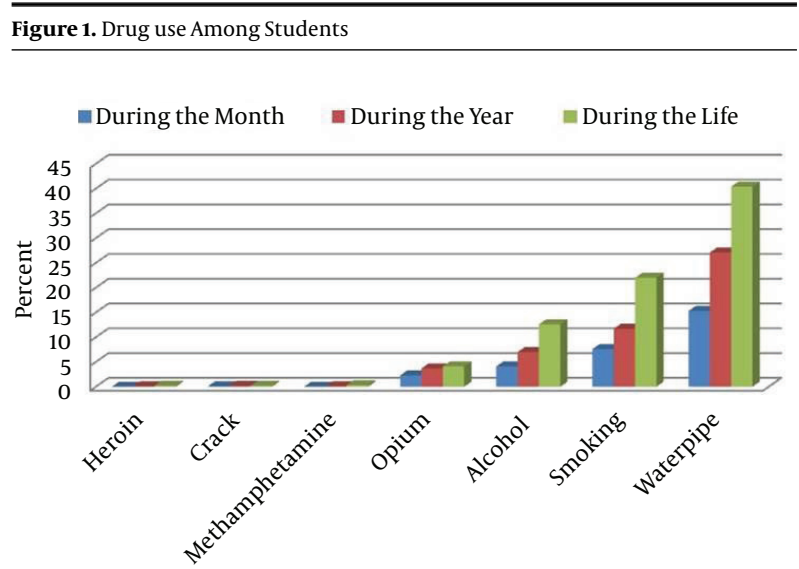

Lifetime prevalence in the last year, and in the last month.

\section{Discussion}

The findings indicated a low prevalence of heavy substance use (opium, marijuana, methamphetamine, heroin) and a high prevalence of light substance use (cigarette, hookah, and alcohol). The prevalence rates of substance use in students for duration of life, the last year, and the last month were $7.5 \%, 5.2 \%$, and $3.7 \%$, respectively. 
Table 1. Demographic Characteristics of Students ${ }^{\mathrm{a}}$

\begin{tabular}{|c|c|}
\hline Variable & Values \\
\hline \multicolumn{2}{|l|}{ Gender } \\
\hline Female & $538(53.1)$ \\
\hline Male & $476(46.9)$ \\
\hline \multicolumn{2}{|l|}{ College } \\
\hline Humanities & $339(33.4)$ \\
\hline Medical Sciences & $216(21.3)$ \\
\hline Technical Engineering & $292(28.8)$ \\
\hline Teacher Training & $103(10.2)$ \\
\hline Basic Sciences & $64(6.3)$ \\
\hline \multicolumn{2}{|l|}{ Citizenship } \\
\hline Native & $849(83.7)$ \\
\hline Foreign & $165(16.3)$ \\
\hline \multicolumn{2}{|l|}{ Degree } \\
\hline \multicolumn{2}{|l|}{ Associate } \\
\hline Female & $122(12.1)$ \\
\hline Male & $111(10.9)$ \\
\hline \multicolumn{2}{|l|}{ Baccalaureate } \\
\hline Female & $401(39.6)$ \\
\hline Male & $349(34.5)$ \\
\hline \multicolumn{2}{|l|}{ Master's Degree } \\
\hline Female & $14(1.4)$ \\
\hline Male & $15(1.5)$ \\
\hline \multicolumn{2}{|l|}{ Age, $y$} \\
\hline $20-18$ & $214(21.1)$ \\
\hline $22-20$ & $266(26.2)$ \\
\hline$>22$ & $523(51.6)$ \\
\hline Undetermined & $11(1.1)$ \\
\hline
\end{tabular}

${ }^{\mathrm{a}}$ Values are expressed as No. (\%).

The prevalence rates of cigarette use in students for duration of life, the last year, and the last month were $22 \%$, $11.7 \%$, and $7.6 \%$, respectively. The prevalence rates of alcohol usage among students for duration of life, the last year, and the last month were $12.6 \%, 7 \%$, and $4.1 \%$, respectively. The prevalence rates of hookah smoking among students for duration of life, the last year, and the last month were $40.4 \%, 27.1 \%$, and $15.3 \%$, respectively.

In a study to determine the prevalence of drug use among university students in Iran conducted by Sarrami et al. over the two decades of research, the researchers showed that $24.3 \%-57.24 \%$ of males and $1.8 \%-27.7 \%$ of females had smoked at least once, with a total prevalence of
$17.3 \%-31.5 \%$. Regular consumption of cigarettes was found in $15.6 \%-30.6 \%$ of males and $5.8 \%-13 \%$ of females, with a total of $14.2 \%-20 \%$. The rate of smoking among males was found to be $2.4 \%-4.7 \%$ (14). The prevalence of drug use among university students in Hamadan showed a lifetime prevalence of drug use among students where the hookah accounted for $46.8 \%$ of drug use, smoking for $28.1 \%$, alcohol for $11.6 \%$, opium for $6.5 \%$, hashish for $0.6 \%$, and heroin pills for $1.9 \%$ (15).

The differences between the results of this research and the findings of other researchers $(14,15)$ may have been due to cultural factors and people's customs in the region in terms of the drugs available at parties. The ministry of health and medical education have warned about the much greater adverse effects of the hookah in comparison to cigarettes, but unfortunately, hookah use is about twice as prevalent as cigarette smoking.

\subsection{Conclusion}

Accelerated development of drug abuse and related problems in the university student population and its harmful outcomes, such as a lack of academic motivation, educational failure, psychological and physical diseases, suicide, destruction of public property, abusive behavior, feelings of a lack of identity, and hazardous sexual behavior, makes it necessity to plan and prepare for preventive interventions in universities.

\section{Acknowledgments}

This study would not have been possible without the help of friends, family, and my dear instructor, Prof. Bakhshani.

\section{References}

1. Capps B, Hall W, Carter A. Addiction, encyclopedia of applied ethic. ; 2012.

2. Siam SH. Drug abuse prevalence between male students of different universities in Rasht in 2005. Tabibe Shargh. 2006;8(4):279-84.

3. Hawkins JD, Catalano RF, Miller JY. Risk and protective factors for alcohol and other drug problems in adolescence and early adulthood: implications for substance abuse prevention. Psychol Bull. 1992;112(1):64105. [PubMed: 1529040 ].

4. White HR, McMorris BJ, Catalano RF, Fleming CB, Haggerty KP, Abbott $\mathrm{RD}$. Increases in alcohol and marijuana use during the transition out of high school into emerging adulthood: The effects of leaving home, going to college, and high school protective factors. J Stud Alcohol. 2006;67(6):810-22. [PubMed: 17060997].

5. American College Health Association-National College Health Assessment Spring 2008 Reference Group Data Report. J Am Coll Health. 2009;57(5):477-88. doi: 10.3200/JACH.57.5.477-488. [PubMed: 19254888].

6. Atwoli L, Mungla PA, Ndung'u MN, Kinoti KC, Ogot EM. Prevalence of substance use among college students in Eldoret, western Kenya. BMC Psychiatry. 2011;11:34. doi: 10.1186/1471-244X-11-34. [PubMed: 21356035]. 
7. Baheiraei A, Hamzehgardeshi Z, Mohammadi MR, Nedjat S, Mohammadi E. Alcohol and drug use prevalence and factors associated with the experience of alcohol use in Iranian adolescents. Iran Red Crescent Med J. 2013;15(3):212-7. doi: 10.5812/ircmj.4022. [PubMed: 23984000].

8. Bakhshani NM, Dahmardei M, Shahraki-Sanavi F, Hosseinbor M, Ansari-Moghaddam A. Substance Abuse Among High School Students in Zahedan. Health Scope. 2014;3(1) doi: 10.17795/jhealthscope-14805.

9. Talaei A, Mokhber N, Fayyazi Bordbar MR, Javanbakht A, Samari AA Patterns and correlates of substance use among university students in Iran. IJ Psychiatr Behav Sci. 2008;2(2):15.

10. Effati J. Addiction Prevention or treatment? [Persian]. Yazd: Niko Ravesh; 2000.

11. Ekhtiyari H. Ways to recognize and treat addiction [Persian]. Tehran:
Arjmand; 2002.

12. Cooper ML. Alcohol use and risky sexual behavior among college students and youth: evaluating the evidence. J Stud Alcohol Suppl. 2002(14):101-17. [PubMed:12022716].

13. Perkins HW. Surveying the damage: a review of research on consequences of alcohol misuse in college populations.J Stud Alcohol Suppl. 2002(14):91-100. [PubMed: 12022733].

14. Sarrami H, Ghorbami M, Taghavi M. The Survey Two Decades of Prevalence Studies among Iran University Students. Res Addict. 2013;7(27):936.

15. Ahmadi M, Soltani T, Behbodi M. Prevalence of substance use among university students in Hamadan. [in Persian]. J Danesh Entezami of Hamadan. 2012;1(1):97-116. 